DR. KATHLEEN A. GRANT (Orcid ID : 0000-0002-0380-7219)

DR. RUSSELL T. TURNER (Orcid ID : 0000-0002-3031-0398)

DR. URSZULA T. IWANIEC (Orcid ID : 0000-0001-6203-0932)

Article type : Original Research Article

\title{
Voluntary Chronic Heavy Alcohol Consumption in Male Rhesus Macaques Suppresses Cancellous Bone Formation and Increases Bone Marrow Adiposity
}

Arianna M. Kahler-Quesada, BS ${ }^{1}$, Kathleen A. Grant, $\mathrm{PhD}^{2}$, Nicole A.R. Walter, BS${ }^{2}$, Natali Newman, $\mathrm{BS}^{2}$, Matthew R. Allen, $\mathrm{PhD}^{3,4}$, David B. Burr, $\mathrm{PhD}^{3,4}$, Adam J. Branscum, $\mathrm{PhD}^{5}$, Gianni F. Maddalozzo, $\mathrm{PhD}^{1}$, Russell T. Turner, $\mathrm{PhD}^{1,6}$, and Urszula T. Iwaniec, $\mathrm{PhD}^{1,6^{*}}$

${ }^{1}$ Skeletal Biology Laboratory, School of Biological and Population Health Sciences, Oregon State University, Corvallis, OR 97331, USA

2Division of Neuroscience, Oregon National Primate Research Center, Oregon Health and Science University, Beaverton, OR 970006, USA

${ }^{3}$ Department of Anatomy and Cell Biology, Indiana University School of Medicine, Indianapolis, IN 46202, USA

${ }^{4}$ Department of Biomedical Engineering, Indiana University-Purdue University, Indianapolis, IN 46202, USA

This is the author's manuscript of the article published in final edited form as:

Kahler - Quesada, A. M., Grant, K. A., Walter, N. A. R., Newman, N., Allen, M. R., Burr, D. B., ... Iwaniec, U. T. (n.d.). Voluntary Chronic Heavy Alcohol Consumption in Male Rhesus Macaques Suppresses Cancellous Bone Formation and Increases Bone Marrow Adiposity. Alcoholism: Clinical and Experimental Research, 0(ja). https://doi.org/10.1111/acer.14202 
${ }^{5}$ Biostatistics Program, School of Biological and Population Health Sciences, Oregon State University, Corvallis, OR 97331, USA

${ }^{6}$ Center for Healthy Aging Research, Oregon State University, Corvallis, OR 97331, USA

Short title: Effects of alcohol on cancellous bone

Word count: 3,904

Support: This work was supported by grants from the National Institutes of Health (AA02689 to UTI and AA013510, AA13641, and AA109431 to KAG). The Endocrine Technologies Core (ETC) at the Oregon National Primate Research Center (ONPRC) was supported by the National Institutes of Health (P51OD011092 to ONPRC)

\section{*Corresponding author:}

Urszula T. Iwaniec, Ph.D.

Skeletal Biology Laboratory

School of Biological and Population Health Sciences

Oregon State University

Corvallis, OR 97331

Tel: 541-737-9925

Fax: 541-737-6914

e-mail: urszula.iwaniec@oregonstate.edu 


\begin{abstract}
Background: Chronic heavy alcohol consumption is an established risk factor for bone fracture but comorbidities associated with alcohol intake may contribute to increased fracture rates in alcohol abusers. To address the specific effects of alcohol on bone, we used a non-human primate model and evaluated voluntary alcohol consumption on (1) global markers of bone turnover in blood and (2) cancellous bone mass, density, microarchitecture, turnover and microdamage in lumbar vertebra.

Methods: Following a 4-month induction period, 6-year-old male rhesus macaques (Macaca mulatta, $n=13)$ voluntarily self-administered water or ethanol $(4 \% \mathrm{w} / \mathrm{v})$ for $22 \mathrm{~h} / \mathrm{d}, 7 \mathrm{~d} / \mathrm{wk}$ for a total of 12 months. Control animals $(n=9)$ consumed an isocaloric maltose-dextrin solution. Tetracycline hydrochloride was administered orally 17 and 3 days prior to sacrifice to label mineralizing bone surfaces. Global skeletal response to ethanol was evaluated by measuring plasma osteocalcin and carboxy-terminal collagen crosslinks (CTX). Local response was evaluated in lumbar vertebra using dual energy X-ray absorptiometry, microcomputed tomography, static and dynamic histomorphometry, and histological assessment of microdamage.
\end{abstract}

Results: Monkeys in the ethanol group consumed an average of $2.8 \pm 0.2$ (mean $\pm S E$ ) $\mathrm{g} / \mathrm{kg} / \mathrm{d}$ of ethanol ( $30 \pm 2 \%$ of total Calories) resulting in an average blood ethanol concentration of $88.3 \pm 8.8$ $\mathrm{mg} / \mathrm{dl} 7$ hours after the session onset. Plasma CTX and osteocalcin tended to be lower in ethanolconsuming monkeys compared to controls. Significant differences in bone mineral density in lumbar vertebrae 1-4 were not detected with treatment. However, cancellous bone volume fraction (in cores biopsied from the central region of the $3^{\text {rd }}$ vertebral body) was lower in ethanol-consuming monkeys compared to controls. Furthermore, ethanol-consuming monkeys had lower osteoblast perimeter and mineralizing perimeter, no significant difference in osteoclast perimeter, and higher bone marrow adiposity than controls. No significant differences between groups were detected in microcrack density ( $2^{\text {nd }}$ lumbar vertebra).

Conclusions: Voluntary chronic heavy ethanol consumption reduces cancellous bone formation in lumbar vertebra by decreasing osteoblast-lined bone perimeter, a response associated with an increase in bone marrow adiposity.

Keywords: Histomorphometry; microcomputed tomography; ethanol; non-human primate; adipocytes.

This article is protected by copyright. All rights reserved 


\section{Introduction}

Alcohol consumption, depending on context, is reported to be associated with beneficial, neutral, or detrimental effects on the skeleton (Gaddini et al., 2016). For example, in early post-menopausal women, moderate alcohol consumption may slow age-related bone loss by reducing bone turnover (Felson et al., 1995, Ganry et al., 2000, Sripanyakorn et al., 2009, Marrone et al., 2012). In contrast, epidemiological studies link chronic alcohol abuse to lower bone mineral density (BMD) (Chappard et al., 1991, Gonzalez-Calvin et al., 1993, Malik et al., 2009) and increased risk of fracture (Berg et al., 2008, Spencer et al., 1986). Since the skeleton undergoes continuous turnover (Frost, 1990), bone loss associated with chronic alcohol abuse may be caused by decreased bone formation and/or increased bone resorption. Most observational studies suggest that chronic alcohol abuse lowers the rate of bone formation (Gonzalez-Calvin et al., 1993, Gonzalez-Reimers et al., 2011, Maurel et al., 2012a), but more variable effects have been reported for bone resorption (Cheung et al., 1995). There is strong evidence that comorbidities, including poor nutrition and disease, contribute to alcohol associated reductions in bone mass and quality (Gaddini et al., 2016), and some, but not all, studies suggest that co-morbidities are essential for alcohol-induced bone loss (Kim et al., 2003, Laitinen et al., 1993).

Variable study outcomes, potentially due to the presence of co-morbidities (Kanis et al., 1999), and difficulty in performing alcohol intervention studies in humans have made the specific effects of alcohol on the skeleton difficult to define. To circumvent the limitations of epidemiological and observational studies, animal models have been widely used to assess the effects of alcohol on bone. Studies conducted in rats have demonstrated detrimental effects of high levels of alcohol consumption on bone accrual during growth (Court-Brown et al., 2012, Gaddini et al., 2016, Turner et al., 2012). The few rodent studies performed following skeletal maturity suggest that chronic consumption of high levels of alcohol results in bone loss and decreased bone strength (Turner et al., 2001, Gaddini et al., 2015, Hogan et al., 2001). A 16-week alcohol intervention study performed in skeletally mature (8-month-old) female rats identified a dose-response suppression in bone formation. Bone resorption was also decreased, but high levels of alcohol resulted in turnover imbalance where resorption exceeded formation, resulting in bone loss (Turner et al., 2001). Similarly, high levels of alcohol consumption resulted in reduced bone formation and cancellous bone loss in skeletally mature male rats (Sibonga et al., 2007).

This article is protected by copyright. All rights reserved 
Using a non-human primate model of voluntary alcohol self-administration, we recently reported that chronic heavy alcohol consumption caused a dramatic reduction in intracortical bone remodeling (Gaddini et al., 2016). However, cortical bone loss was not evident. Based on studies performed in skeletally mature rodents, alcohol-induced bone loss occurs preferentially at cancellous sites. It is unknown whether compartment-specific bone loss in response to alcohol is generalizable to nonrodent animal models, including non-human primates. Due to their high genetic and behavioral homology to humans, rhesus macaques are a useful model to evaluate the effects of alcohol on the skeleton. Furthermore, macaques display voluntary alcohol consumption patterns remarkably similar to humans, including marked variability among subjects in amount and pattern of alcohol consumed (Mello and Mendelson, 1971, Vivian et al., 2001, Baker et al., 2014). We therefore evaluated the effect of chronic alcohol consumption on cancellous bone mass, architecture, and turnover in young adult male rhesus macaques.

\section{Materials and Methods}

\section{Animals}

The study population consisted of $22(\mathrm{n}=9$ control and 13 ethanol) young adult ( $5.9 \pm 0.1$ years old at start of treatment) male rhesus macaques (Macaca mulatta) representing 2 experimental cohorts well matched for age and weight; cohort Rhesus 5 ( $n=5$ control and 8 ethanol) and cohort Rhesus $7 \mathrm{~b}$ ( $\mathrm{n}=4$ control and 5 ethanol). All of the monkeys were born and reared in captivity at the Oregon National Primate Research Center at Oregon Health and Sciences University and both cohorts were subjected to the same experimental protocol (below). Monkeys were individually housed in a humidity- $(65 \%)$, temperature- $\left(20-22^{\circ} \mathrm{C}\right)$, and light-controlled (light on $0700-1800$ hours) room that allowed visual, auditory, and olfactory contact among the animals. Ethanol intake was recorded continuously and blood ethanol concentrations (BECs) were measured every 5 days (Helms et al., 2014, Kroenke et al., 2014). Details of the daily intakes and BECs of all subjects in cohorts 5 and $7 \mathrm{~b}$ are available through the Monkey Alcohol Tissue Resource (MATRR.com) (Daunais et al., 2014).

\section{Experimental Protocol}

The experimental protocol is described in detail elsewhere (Gaddini et al., 2015, Grant et al., 2008). In brief, the protocol consisted of an induction phase (120 days) and a voluntary drinking

This article is protected by copyright. All rights reserved 
phase (12 months). During the induction phase, the monkeys were trained to use an operant panel and induced to drink increasing volumes of an ethanol solution in a step-wise fashion over 4 consecutive 30-day periods, starting with water only during the initial 30-day period. During the 12month voluntary drinking phase, monkeys in the ethanol group were given free access to water and ethanol ( $4 \% \mathrm{w} / \mathrm{v}$ in water) for $22 \mathrm{~h} / \mathrm{d}, 7 \mathrm{~d} / \mathrm{wk}$. Control animals were allowed to self-administer a volume of maltose-dextrin solution isocaloric to the previous week's average volume of ethanol consumed by an ethanol animal assigned at baseline (i.e., a yoked control).

The fluorochrome tetracycline hydrochloride $(20 \mathrm{mg} / \mathrm{kg})$ was administered orally 17 and 3 days prior to sacrifice for determination of active mineralization sites and rates of bone formation. Venous blood was collected at necropsy and plasma samples stored at $-80^{\circ} \mathrm{C}$ until analysis of markers of bone turnover. Lumbar vertebrae 1-4 (LV 1-4) were then harvested, placed in $70 \%$ ethanol, and stored at $4^{\circ} \mathrm{C}$ until analysis.

\section{Blood Ethanol Concentrations}

Awake blood samples $(20 \mu \mathrm{l})$ were collected from the medial saphenous vein approximately every 5 days at 7 hours into the daily drinking session. Samples were diluted in sterile water and stored at $-4^{\circ} \mathrm{C}$ until assayed using headspace gas chromatography (Agilent Technologies, Santa Clara, CA).

\section{Blood Concentrations of Markers of Bone Turnover}

Plasma carboxyterminal cross-linking telopeptide of type 1 collagen (CTX, a marker of global bone resorption) and osteocalcin (a marker of global bone formation) were measured at necropsy in control monkeys and at baseline and necropsy in ethanol-consuming monkeys; blood was not available from control animals at baseline. Assays were conducted by the Endocrine Technologies Core (ETC) at the Oregon National Primate Research Center using a Roche Cobas e411 Automated Clinical Platform (Roche Diagnostics, Indianapolis, IN). The assays were validated for use in nonhuman primates by the ETC. The assay ranges of the CTX and osteocalcin assays were $0.01-$ $6.00 \mathrm{ng} / \mathrm{ml}$ and $0.5-300 \mathrm{ng} / \mathrm{ml}$, respectively. Intra-assay coefficient of variation (CV) for CTX was $1.1 \%$ and intra-assay CV for osteocalcin was $7.8 \%$. Because all samples were measured the same day no inter-assay CV was calculated for these specimens; the ETC inter-assay CV for CTX and osteocalcin are $2.4 \%$ and $5.0 \%$, respectively.

This article is protected by copyright. All rights reserved 


\section{Dual-Energy X-Ray Absorptiometry}

Bone area $\left(\mathrm{cm}^{2}\right)$, bone mineral content $(\mathrm{BMC}, \mathrm{g})$, and areal BMD $\left(\mathrm{g} / \mathrm{cm}^{2}\right)$ were determined post mortem in harvested (isolated and soft tissue removed) LV 1-4 using dual-energy X-ray absorptiometry (DXA) (Hologic Discovery A, Waltham, MA; Hologic APEX System Software, Version 3.1.1). Quality control check was performed against the Anthropomorphic Spine Phantom and Small Animal Step Phantom provided by the manufacturer. The coefficient of variation evaluating testretest reliability for bone area, BMC, and BMD for DXA scans in our laboratory is $1.0 \%$. The least significant difference is $0.003-0.006 \mathrm{~g} / \mathrm{cm}^{2}$, depending on skeletal site, at the $95 \%$ confidence level.

\section{Microcomputed Tomography}

Microcomputed tomography $(\mu \mathrm{CT})$ was used for 3-dimensional evaluation of cancellous bone microarchitecture in the $3^{\text {rd }}$ lumbar vertebra. Vertebral bodies were scanned in $70 \%$ ethanol at a voxel size of $36 \times 36 \times 36 \mu \mathrm{m}(55 \mathrm{kVp}, 145 \mu \mathrm{A}$, and $200 \mathrm{~ms}$ integration time) using a Scanco $\mu$ CT40 scanner (Scanco Medical AG, Basserdorf, Switzerland). For evaluation, filtering parameters sigma and support were set to 0.8 and 1 , respectively. Cancellous bone in the vertebral body (volume of interest, $1559 \pm 95 \mathrm{~mm}^{3}$; Figure 1A), 3 slices $(108 \mu \mathrm{m})$ away from the endplate primary spongiosa, was analyzed at a threshold of 175 (gray scale of 0-1000) determined empirically. The region of interest included cancellous bone only between the cranial and caudal growth plates. Cancellous bone measurements included cancellous bone volume fraction (bone volume/tissue volume \%), connectivity density $\left(\mathrm{mm}^{-3}\right)$, trabecular thickness $(\mu \mathrm{m})$, trabecular number $\left(\mathrm{mm}^{-1}\right)$, and trabecular separation $(\mu \mathrm{m})$. Subsequently, biopsies $(7.1 \mathrm{~mm}$ in diameter) were removed from the central portion of the vertebral body using a Ryobi DP102 drill and scanned at a voxel size of $12 \times 12 \times 12$ $\mu \mathrm{m}(55 \mathrm{kVp}, 145 \mu \mathrm{A}$, and $200 \mathrm{~ms}$ integration time). Cancellous bone in the biopsy (volume of interest, $162 \pm 3 \mathrm{~mm}^{3}$; Figure 1B) was analyzed at a threshold of 220 . The biopsy was subsequently embedded for histomorphometric evaluation.

\section{Quantitative Bone Histomorphometry}

Specimens were prepared for histomorphometric evaluation as previously described (Iwaniec et al., 2008). In brief, the vertebral biopsy cores were dehydrated in a graded series of ethanol and xylene, and embedded undecalcified in modified methyl methacrylate. $4 \mu \mathrm{m}$ thick longitudinal sections were cut using a vertical bed microtome (Leica 2065) and affixed to gel slides (pre-coated

This article is protected by copyright. All rights reserved 
with $1 \%$ gelatin solution). One histological section/animal was stained according to the von Kossa method followed by tetrachrome counterstain and used for cell-based measurements. A second, non-serial section was mounted unstained for measurement of fluorochrome labels.

Cancellous bone was evaluated in a region of interest $\left(6 \mathrm{~mm}^{2}\right)$ located in the cranial portion of the core $0.25 \mathrm{~mm}$ caudal to the growth plate cartilage (Figure 1C). Static measurements included osteoid area (osteoid area/bone area, \%), osteoid thickness $(\mu \mathrm{m})$, osteoid perimeter (osteoid perimeter/bone perimeter, \%), osteoblast perimeter (osteoblast perimeter/bone perimeter, \%), osteoclast perimeter (osteoclast perimeter/bone perimeter, \%), marrow adipose tissue area (adipocyte area/tissue area, \%), adipocyte density (number of adipocytes $/ \mathrm{mm}^{2}$ ), and adipocyte size $\left(\mu \mathrm{m}^{2}\right)$. Fluorochrome-based measurements of cancellous bone remodeling included mineralizing perimeter (mineralizing perimeter/bone perimeter: perimeter covered with double label plus half single label, normalized to bone perimeter, \%), mineral apposition rate (the distance between double fluorochrome labels, divided by the 14 day period between label administration, $\mu \mathrm{m} / \mathrm{day}$ ), and bone formation rate (mineralizing perimeter multiplied by mineral apposition rate expressed per bone perimeter $\left(\mu \mathrm{m}^{2} / \mu \mathrm{m} / \mathrm{y}\right)$, bone area $(\% / \mathrm{y})$, and tissue area $\left.(\% / \mathrm{y})\right)$.

All histomorphometric data were collected using an Olympus $\mathrm{BH} 2$ Microscope (Olympus, Shinjuku, Tokyo, Japan) equipped with an Olympus DP71 microscope digital camera (Olympus, Shinjuku, Tokyo, Japan) and attached to a computer system with OsteoMeasure software (OsteoMetrics, Atlanta, GA).

\section{Microdamage Assessment}

Microdamage was assessed in the $2^{\text {nd }}$ lumbar vertebra. The body of each vertebra was isolated and bulk stained in basic fuchsin using established protocols (Allen et al., 2006, Burr and Hooser, 1995). Semi-thin ( 120 um) sagittal sections were cut using a diamond wire saw and mounted to glass slides. One specimen in each group was damaged during processing. The cancellous bone within a $\sim 25 \mathrm{~mm}^{2}$ region of interest near the cranial end was assessed for linear microcracks. Outcome parameters include average crack length $(\mu \mathrm{m})$, crack density (crack number/bone area, $\# / \mathrm{mm}^{2}$ ), and crack surface density (crack number * mean crack length/bone area, $\mu \mathrm{m} / \mathrm{mm}^{2}$ ).

\section{Statistical Analysis}

This article is protected by copyright. All rights reserved 
Mean comparisons between the ethanol and control groups were made using t-tests with equal variances, Welch's t-test, or the Wilcoxon-Mann-Whitney test, with the selection of significance test determined from evaluating the assumptions of homogeneity of variance (using Levene's test and residual plots) and normality (using normal quantile plots and the Anderson-Darling test). Mean comparisons for CTX and osteocalcin were made using one-way analysis of variance applied to data from the control group at necropsy and ethanol groups at baseline and necropsy. Adjustment for multiple comparisons was made by controlling the false discovery rate at $\leq 5 \%$ (Benjamini and Hochberg, 1995). Differences were considered significant at $p \leq 0.05$. All data are presented as mean \pm SE. Data analysis was performed using $\mathrm{R}$ version 3.4.3.

\section{Results}

Characteristics of the study population are shown in Table 1. Age and body weight did not differ between control and ethanol monkeys. Monkeys in the ethanol group consumed an average of $2.8 \pm 0.2 \mathrm{~g} / \mathrm{kg} / \mathrm{d}$ of ethanol $(29.6 \pm 2.4 \%$ of total Calories) resulting in an average BEC of $88.3 \pm 8.8 \mathrm{mg} / \mathrm{dl}$ 7 hours after the session onset.

The effects of ethanol consumption on bone area, BMC and BMD in lumbar vertebrae 1-4 are shown in Figure 2. No significant group differences were detected for either vertebral bone area (Figure 2A), BMC (Figure 2B), or BMD (Figure 2C).

The effects of ethanol consumption on cancellous bone architecture in the $3^{\text {rd }}$ lumbar vertebra are shown in Figure 3. Vertebral body cancellous bone volume fraction (Figure 3A) and trabecular thickness (Figure 3C) tended to be lower ( $p=0.10$ for both) in ethanol-consuming monkeys compared to controls. However, no significant differences in connectivity density (Figure 3B), trabecular number (Figure 3D), or trabecular separation (Figure 3E) were detected with treatment. Cancellous bone volume fraction (Figure 3F) was significantly lower and trabecular thickness (Figure $3 \mathrm{H})$ tended to be lower $(p=0.10)$ in cores biopsied from the central region of the vertebral body (Figure 1) and scanned at smaller voxel size for improved resolution. However, as in total vertebral body, no significant differences in connectivity density (Figure 3G), trabecular number

(Figure 3I), or trabecular separation (Figure 3J) were detected with treatment in the core biopsies. Evaluation of a relatively small biopsy (162 $\pm 3 \mathrm{~mm}^{3}$ in volume) led to comparable conclusions as evaluation of the entire cancellous compartment $\left(1559 \pm 95 \mathrm{~mm}^{3}\right)$. This finding provides evidence

This article is protected by copyright. All rights reserved 
that measurements performed on tissue obtained from the longitudinal biopsy reflect the entire cancellous compartment.

The effects of ethanol consumption on cellular indices of bone formation, bone resorption, and marrow adiposity are shown in Figure 4. No significant differences in osteoid area (Figure 4A) and osteoid thickness (Figure 4B) were detected with treatment. However, osteoid perimeter (Figure 4C) tended to be lower $(p=0.07)$ and osteoblast perimeter (Figure 4D) was significantly lower in monkeys consuming ethanol compared to controls. Marrow adiposity (Figure 4F) and adipocyte size (Figure 4H) were significantly higher, and adipocyte density (Figure 4G) tended to be higher $(p=$ $0.10)$ in monkeys consuming ethanol compared to controls. No significant differences in osteoclast perimeter, an index of bone resorption, were detected with treatment (Figure 4E).

The effects of ethanol consumption on dynamic indices of bone formation are shown in Figure 5. Mineralizing perimeter (Figure 5A) and bone formation rate, expressed per bone perimeter (Figure 5C), bone area (Figure 5D), and tissue area (Figure 5E) were significantly lower in ethanolconsuming monkeys compared to controls. No significant differences in mineral apposition rate (Figure 5B) were detected with treatment. Representative images from a control and ethanolconsuming monkey are shown in Figure 5F and 5G, respectively.

The effects of ethanol consumption on microcracks in the $2^{\text {nd }}$ lumbar vertebra are shown in Figure 6. Alcohol consumption had no significant effect on crack density (Figure 6A), crack surface density (Figure 6B), or mean crack length (Figure 6C).

The effects of ethanol consumption on plasma CTX (a marker of global bone resorption) and osteocalcin (a marker of global bone formation) are shown in Figure 7. CTX (Figure 7A) decreased significantly and osteocalcin (Figure 7B) tended to decrease $(p=0.053)$ in ethanol-consuming monkeys compared to baseline values and both markers tended to be lower $(p=0.070$ and $p=0.10$, respectively) in ethanol-consuming monkeys compared to controls at termination of treatment.

\section{Discussion}

We investigated the cumulative effects of voluntary alcohol consumption on markers of global bone turnover and on bone density, cancellous bone microarchitecture, cancellous bone resorption and formation, and microdamage in lumbar vertebra of healthy young adult male rhesus macaques. 
Average intake of $2.8 \mathrm{~g}$ ethanol $/ \mathrm{kg} / \mathrm{d}$ (average BEC, $88 \mathrm{mg} / \mathrm{dl}$ ), accounting for $30 \%$ of caloric intake, had no significant effect on BMD. However, cancellous bone volume fraction and bone formation were reduced and marrow adipose tissue levels were increased in alcohol-consuming monkeys compared to controls. Blood markers of bone turnover tended to be lower in monkeys consuming alcohol. Levels of microdamage in the cancellous bone did not differ between treatment groups.

Cancellous bone plays a fundamental role in mineral homeostasis, and low-trauma fractures in adults often occur at skeletal sites rich in cancellous bone (Hans et al., 2017, Beaudoin et al., 2018). In the present study, chronic alcohol consumption resulted in lower bone formation, as evidenced by lower osteoblast-lined bone perimeter, mineralizing bone perimeter and a tendency for lower plasma osteocalcin levels. The modest reduction in cancellous bone volume fraction in lumbar vertebra, in spite of decreased bone formation, is most likely due to a concurrent decrease in bone resorption. Normal or elevated bone resorption would have led to much greater bone loss. While we did not detect a change in osteoclast-lined bone perimeter in the lumbar vertebra, plasma CTX tended to be lower in alcohol-consuming monkeys, suggesting a global reduction in bone resorption. Thus, it is plausible that osteoclast activity was reduced by alcohol. In support, moderate alcohol intake (3 and $6 \%$ of total calories) lowered cancellous bone turnover (resorption and formation) in skeletally mature female rats without influencing bone mass, whereas higher alcohol intake (13 and 35\% of total calories) resulted in bone loss (Turner et al., 2001). These results implied that moderate levels of alcohol consumption lowered bone turnover while preserving a neutral bone balance whereas high levels resulted in a negative bone turnover balance. Our failure to detect a reduction in BMD in the present study differs from the reduction typically observed in young rodents where alcohol inhibited bone growth (Maurel et al., 2011), and suggests that although alcohol resulted in a negative turnover balance in the young adult male monkeys, the duration of exposure was insufficient to detect changes with DXA. Alternatively, reduced cortical porosity (Gaddini et al., 2015) may have compensated for reduced bone volume fraction in the cancellous compartment, resulting in no net change in BMD.

Heavy alcohol consumption increases bone marrow adiposity in growing rodents (Maddalozzo et al., 2009, Alund et al., 2017, Howe et al., 2011, Maurel et al., 2012b), a response observed in the present study in young adult male rhesus macaques. Osteoblasts and bone marrow adipocytes originate from the same bone marrow mesenchymal stem cells, and in vitro studies suggest that, at high concentrations, alcohol decreases osteoblast number by modulating the differentiation program 
of stem cells to form adipocytes at the expense of osteoblasts (Chen et al., 2010, Wezeman and Gong, 2004). However, there is also evidence that osteoblasts and marrow adipocytes are regulated independently (Turner et al., 2018). Specifically, we have shown that neither pathological increases in marrow adiposity following hypophysectomy in rats (Menagh et al., 2010) nor absence of marrow adiposity in mice with loss of function mutations in c-kit signaling (Iwaniec and Turner, 2013, Keune et al., 2017) influence the skeletal response to bone anabolic or catabolic factors.

Treatment with antioxidants were reported to attenuate alcohol-induced increases in marrow adipose tissue in mice, suggesting that increased oxidative stress contributes to fat accrual in the mouse model (Alund et al., 2017). Disruption of growth hormone signaling represents an alternative, non-mutually exclusive mechanism. Surgical and genetic growth hormone deficiency result in excess accrual of fat into bone marrow and alcohol results in end-organ resistance, blunting the ability of growth hormone to lower bone marrow adiposity in rats (Menagh et al., 2010, Turner et al., 2010). In this regard, proteomic studies provide evidence (lower IGF-1 serum levels) for reduced growth hormone signaling in alcohol consuming monkeys (Helms et al., 2012) and the low turnover bone loss observed in the current study is consistent with cellular mechanism for reduced bone mass associated with growth hormone deficiency (Menagh et al., 2010).

There has been a recent upsurge in interest in the role of marrow adipose tissue in health and disease (Li et al., 2018, Veldhuis-Vlug and Rosen, 2018) with most research focusing on bone marrow adipocytes as likely negative modulators of bone remodeling balance (Turner et al., 2018, Veldhuis-Vlug and Rosen, 2018). However, research using genetic models has led to the proposal that changes in marrow adiposity reflect physiological adaptation. Specifically, marrow adipose tissue serves as an expandable/contractible fat depot to minimize energy requirements for sustaining optimal hematopoiesis. Based on this model, metabolic coupling between mesenchymal and hematopoietic cells in bone marrow regulates MAT levels. Thus, the well-established inhibitory effects of chronic alcohol consumption on hematopoiesis may be responsible for increased MAT here and in rodent models (Heermans, 1998, Siggins et al., 2009, Turner et al., 2018).

As mentioned, twelve months of voluntary alcohol consumption in male rhesus macaques suppressed intracortical bone remodeling and decreased cortical bone porosity without altering BMD (Gaddini et al., 2015). These earlier findings suggest that alcohol, while inhibiting initiation of osteonal remodeling and slowing bone formation, did not prevent completion of osteons. In the

This article is protected by copyright. All rights reserved 
present study, we used imaging tools more sensitive than those available for routine clinical evaluation and detected modest alcohol-induced changes in cancellous bone architecture. Therefore, alcohol may have a negative effect on bone not detected by measurement of BMD or trabecular bone score, which are the principal tools used in clinical practice to assess fracture risk (Hans et al., 2017).

Accumulation of microdamage may contribute to increased skeletal fragility with age and disease (Burr et al., 1997). The skeleton undergoes continuous remodeling, which functions, in part, to repair fatigue-induced microcracks (Allen and Burr, 2011). Not surprisingly, reduced bone remodeling is associated with accumulation of microdamage (Allen and Burr, 2011). For example, treatment of dogs for one year with clinically relevant doses of bisphosphonates, a class of drug that preserves bone by suppressing bone resorption, increased microcrack length and density (Mashiba et al., 2001). The absence of significant increases in microcrack density or mean crack length in the $2^{\text {nd }}$ lumbar vertebra in the present study suggests that bone remodeling was sufficient to prevent accrual of cancellous bone microdamage during 12 months of voluntarily alcohol consumption. Longer duration studies will be required to verify this conclusion.

The specific effects of alcohol on bone are likely mediated by both direct and indirect mechanisms. In cell culture, alcohol increases indices of bone resorption by osteoclasts and decreases markers of bone formation by osteoblasts (Chavassieux et al., 1993, Cheung et al., 1995, Turner, 2000). Mechanistically, there is evidence that alcohol-induced oxidative stress impairs osteoblast differentiation (Chen et al., 2009). In addition, alcohol has been associated with altered levels and/or signaling of several hormones that affect bone metabolism (Ronis et al., 2007). These include calcium-regulating hormones that mediate mineral homeostasis (e.g., Vitamin D and PTH), growth hormones (e.g., growth hormone and IGF-I), and reproductive hormones (e.g., estrogen and androgens) (Gaddini et al., 2016, Turner, 2000, Turner et al., 2012, Chen et al., 2009, Ronis et al., 2007, Shankar et al., 2008). In addition, malnutrition is often associated with chronic alcohol abuse, and may lead to further mineral and hormone imbalances (Gonzalez-Reimers et al., 2011). Further study will be required to determine the specific effects of alcohol on bone regulating hormones and lifestyle factors in this model.

In summary, 12 months of alcohol consumption, at caloric intake levels (30\%) commonly observed in alcohol abusers (Gaddini et al., 2016), reduced cancellous bone volume fraction in 
lumbar vertebrae in young adult male rhesus macaques. In concordance with a prior study evaluating cortical bone remodeling (Gaddini et al., 2015), the detrimental skeletal response to heavy alcohol consumption was due, in part, to reduced bone formation. Future studies evaluating female and older male macaques are required to establish the generalizability of these results.

This article is protected by copyright. All rights reserved 


\section{References}

ALLEN, M. R. \& BURR, D. B. 2011. Bisphosphonate effects on bone turnover, microdamage, and mechanical properties: what we think we know and what we know that we don't know. Bone, 49, 56-65.

ALLEN, M. R., IWATA, K., PHIPPS, R. \& BURR, D. B. 2006. Alterations in canine vertebral bone turnover, microdamage accumulation, and biomechanical properties following 1-year treatment with clinical treatment doses of risedronate or alendronate. Bone, 39, 872-9.

ALUND, A. W., MERCER, K. E., PULLIAM, C. F., SUVA, L. J., CHEN, J. R., BADGER, T. M. \& RONIS, M. J. 2017. Partial protection by dietary antioxidants against ethanol-induced osteopenia and changes in bone morphology in female mice. Alcohol Clin Exp Res, 41, 46-56.

BAKER, E. J., FARRO, J., GONZALES, S., HELMS, C. \& GRANT, K. A. 2014. Chronic alcohol self-administration in monkeys shows long-term quantity/frequency categorical stability. Alcohol Clin Exp Res, 38, 2835-43.

BEAUDOIN, C., JEAN, S., MOORE, L., GAMACHE, P., BESSETTE, L., STE-MARIE, L. G. \& BROWN, J. P. 2018. Number, location, and time since prior fracture as predictors of future fracture in the elderly from the general population. J Bone Miner Res, 33, 1956-1966.

BENJAMINI, Y. \& HOCHBERG, Y. 1995. Controlling the false discovery rate: a practical and powerful approach to multiple testing. Journal of the Royal Statistical Society Series B, 57, 289-300.

BERG, K. M., KUNINS, H. V., JACKSON, J. L., NAHVI, S., CHAUDHRY, A., HARRIS, K. A., JR., MALIK, R. \& ARNSTEN, J. H. 2008. Association between alcohol consumption and both osteoporotic fracture and bone density. Am J Med, 121, 406-18.

BURR, D. B., FORWOOD, M. R., FYHRIE, D. P., MARTIN, R. B., SCHAFFLER, M. B. \& TURNER, C. H. 1997. Bone microdamage and skeletal fragility in osteoporotic and stress fractures. J Bone Miner Res, 12, 6-15.

BURR, D. B. \& HOOSER, M. 1995. Alterations to the en bloc basic fuchsin staining protocol for the demonstration of microdamage produced in vivo. Bone, 17, 431-3.

CHAPPARD, D., PLANTARD, B., PETITJEAN, M., ALEXANDRE, C. \& RIFFAT, G. 1991. Alcoholic cirrhosis and osteoporosis in men: a light and scanning electron microscopy study. J Stud Alcohol, 52, 269-74.

CHAVASSIEUX, P., SERRE, C. M., VERGNAUD, P., DELMAS, P. D. \& MEUNIER, P. J. 1993. In vitro evaluation of dose-effects of ethanol on human osteoblastic cells. Bone Miner, 22, 95-103.

This article is protected by copyright. All rights reserved 
CHEN, J. R., LAZARENKO, O. P., HALEY, R. L., BLACKBURN, M. L., BADGER, T. M. \& RONIS, M. J. 2009. Ethanol impairs estrogen receptor signaling resulting in accelerated activation of senescence pathways, whereas estradiol attenuates the effects of ethanol in osteoblasts. J Bone Miner Res, 24, 221-30.

CHEN, J. R., LAZARENKO, O. P., SHANKAR, K., BLACKBURN, M. L., BADGER, T. M. \& RONIS, M. J. 2010. A role for ethanol-induced oxidative stress in controlling lineage commitment of mesenchymal stromal cells through inhibition of Wnt/beta-catenin signaling. J Bone Miner Res, 25, 1117-27.

CHEUNG, R. C., GRAY, C., BOYDE, A. \& JONES, S. J. 1995. Effects of ethanol on bone cells in vitro resulting in increased resorption. Bone, 16, 143-7.

COURT-BROWN, C. M., BUGLER, K. E., CLEMENT, N. D., DUCKWORTH, A. D. \& MCQUEEN, M. M. 2012. The epidemiology of open fractures in adults. A 15-year review. Injury, 43, 891-7.

DAUNAIS, J. B., DAVENPORT, A. T., HELMS, C. M., GONZALES, S. W., HEMBY, S. E., FRIEDMAN, D. P., FARRO, J. P., BAKER, E. J. \& GRANT, K. A. 2014. Monkey alcohol tissue research resource: banking tissues for alcohol research. Alcohol Clin Exp Res, 38, 1973-81.

FELSON, D. T., ZHANG, Y., HANNAN, M. T., KANNEL, W. B. \& KIEL, D. P. 1995. Alcohol intake and bone mineral density in elderly men and women. The Framingham Study. Am J Epidemiol, 142, 485-92.

FROST, H. M. 1990. Skeletal structural adaptations to mechanical usage (SATMU): 2. Redefining Wolff's law: the remodeling problem. Anat Rec, 226, 414-22.

GADDINI, G. W., GRANT, K. A., WOODALL, A., STULL, C., MADDALOZZO, G. F., ZHANG, B., TURNER, R. T. \& IWANIEC, U. T. 2015. Twelve months of voluntary heavy alcohol consumption in male rhesus macaques suppresses intracortical bone remodeling. Bone, 71, 227-36.

GADDINI, G. W., TURNER, R. T., GRANT, K. A. \& IWANIEC, U. T. 2016. Alcohol: a simple nutrient with complex actions on bone in the adult skeleton. Alcohol Clin Exp Res, 40, 657-71.

GANRY, O., BAUDOIN, C. \& FARDELLONE, P. 2000. Effect of alcohol intake on bone mineral density in elderly women: The EPIDOS Study. Epidemiologie de I'Osteoporose. Am J Epidemiol, 151, 773-80.

GONZALEZ-CALVIN, J. L., GARCIA-SANCHEZ, A., BELLOT, V., MUNOZ-TORRES, M., RAYA-ALVAREZ, E. \& SALVATIERRA-RIOS, D. 1993. Mineral metabolism, osteoblastic function and bone mass in chronic alcoholism. Alcohol Alcohol, 28, 571-9.

This article is protected by copyright. All rights reserved 
GONZALEZ-REIMERS, E., ALVISA-NEGRIN, J., SANTOLARIA-FERNANDEZ, F., CANDELARIA MARTIN-GONZALEZ, M., HERNANDEZ-BETANCOR, I., FERNANDEZ-RODRIGUEZ, C. M., VINA-RODRIGUEZ, J. \& GONZALEZDIAZ, A. 2011. Vitamin D and nutritional status are related to bone fractures in alcoholics. Alcohol Alcohol, 46, 148-55.

GRANT, K. A., LENG, X., GREEN, H. L., SZELIGA, K. T., ROGERS, L. S. \& GONZALES, S. W. 2008. Drinking typography established by scheduled induction predicts chronic heavy drinking in a monkey model of ethanol self-administration. Alcohol Clin Exp Res, 32, 1824-38.

HANS, D., STENOVA, E. \& LAMY, O. 2017. The Trabecular Bone Score (TBS) complements DXA and the FRAX as a fracture risk assessment tool in routine clinical practice. Curr Osteoporos Rep, 15, 521-531.

HEERMANS, E. H. 1998. Booze and blood: the effects of acute and chronic alcohol abuse on the hematopoietic system. Clin Lab Sci, 11, 229-32.

HELMS, C. M., MESSAOUDI, I., JENG, S., FREEMAN, W. M., VRANA, K. E. \& GRANT, K. A. 2012. A longitudinal analysis of circulating stress-related proteins and chronic ethanol self-administration in cynomolgus macaques. Alcohol Clin Exp Res, 36, 995-1003.

HELMS, C. M., RAU, A., SHAW, J., STULL, C., GONZALES, S. W. \& GRANT, K. A. 2014. The effects of age at the onset of drinking to intoxication and chronic ethanol self-administration in male rhesus macaques. Psychopharmacology (Berl), 231, 1853-61.

HOGAN, H. A., ARGUETA, F., MOE, L., NGUYEN, L. P. \& SAMPSON, H. W. 2001. Adult-onset alcohol consumption induces osteopenia in female rats. Alcohol Clin Exp Res, 25, 746-54.

HOWE, K. S., IWANIEC, U. T. \& TURNER, R. T. 2011. The effects of low dose parathyroid hormone on lumbar vertebrae in a rat model for chronic alcohol abuse. Osteoporos Int, 22, 1175-81.

IWANIEC, U. T. \& TURNER, R. T. 2013. Failure to generate bone marrow adipocytes does not protect mice from ovariectomy-induced osteopenia. Bone, 53, 145-53.

IWANIEC, U. T., WRONSKI, T. J. \& TURNER, R. T. 2008. Histological analysis of bone. Methods Mol Biol, 447, $325-41$.

KANIS, J., JOHNELL, O., GULLBERG, B., ALLANDER, E., ELFFORS, L., RANSTAM, J., DEQUEKER, J., DILSEN, G., GENNARI, C., VAZ, A. L., LYRITIS, G., MAZZUOLI, G., MIRAVET, L., PASSERI, M., PEREZ CANO, R.,

This article is protected by copyright. All rights reserved 
RAPADO, A. \& RIBOT, C. 1999. Risk factors for hip fracture in men from southern Europe: the MEDOS study. Mediterranean Osteoporosis Study. Osteoporos Int, 9, 45-54.

KEUNE, J. A., WONG, C. P., BRANSCUM, A. J., IWANIEC, U. T. \& TURNER, R. T. 2017. Bone marrow adipose tissue deficiency increases disuse-induced bone loss in male mice. Sci Rep, 7, 46325.

KIM, M. J., SHIM, M. S., KIM, M. K., LEE, Y., SHIN, Y. G., CHUNG, C. H. \& KWON, S. O. 2003. Effect of chronic alcohol ingestion on bone mineral density in males without liver cirrhosis. Korean J Intern Med, 18, 174-80.

KROENKE, C. D., ROHLFING, T., PARK, B., SUlLIVAN, E. V., PFEFFERBAUM, A. \& GRANT, K. A. 2014. Monkeys that voluntarily and chronically drink alcohol damage their brains: a longitudinal MRI study. Neuropsychopharmacology, 39, 823-30.

LAITINEN, K., KARKKAINEN, M., LALLA, M., LAMBERG-ALLARDT, C., TUNNINEN, R., TAHTELA, R. \& VALIMAKI, M. 1993. Is alcohol an osteoporosis-inducing agent for young and middle-aged women? Metabolism, $42,875-81$.

LI, Z., HARDIJ, J., BAGCHI, D. P., SCHELLER, E. L. \& MACDOUGALD, O. A. 2018. Development, regulation, metabolism and function of bone marrow adipose tissues. Bone, 110, 134-140.

MADDALOZZO, G. F., TURNER, R. T., EDWARDS, C. H., HOWE, K. S., WIDRICK, J. J., ROSEN, C. J. \& IWANIEC, U. T. 2009. Alcohol alters whole body composition, inhibits bone formation, and increases bone marrow adiposity in rats. Osteoporos Int, 20, 1529-38.

MALIK, P., GASSER, R. W., KEMMLER, G., MONCAYO, R., FINKENSTEDT, G., KURZ, M. \& FLEISCHHACKER, W. W. 2009. Low bone mineral density and impaired bone metabolism in young alcoholic patients without liver cirrhosis: a cross-sectional study. Alcohol Clin Exp Res, 33, 375-81.

MARRONE, J. A., MADDALOZZO, G. F., BRANSCUM, A. J., HARDIN, K., CIALDELLA-KAM, L., PHILBRICK, K. A., BREGGIA, A. C., ROSEN, C. J., TURNER, R. T. \& IWANIEC, U. T. 2012. Moderate alcohol intake lowers biochemical markers of bone turnover in postmenopausal women. Menopause, 19, 974-9.

MASHIBA, T., TURNER, C. H., HIRANO, T., FORWOOD, M. R., JOHNSTON, C. C. \& BURR, D. B. 2001. Effects of suppressed bone turnover by bisphosphonates on microdamage accumulation and biomechanical properties in clinically relevant skeletal sites in beagles. Bone, 28, 524-31.

This article is protected by copyright. All rights reserved 
MAUREL, D. B., BOISSEAU, N., BENHAMOU, C. L. \& JAFFRE, C. 2012a. Alcohol and bone: review of dose effects and mechanisms. Osteoporos Int, 23, 1-16.

MAUREL, D. B., JAFFRE, C., ROCHEFORT, G. Y., AVELINE, P. C., BOISSEAU, N., UZBEKOV, R., GOSSET, D., PICHON, C., FAZZALARI, N. L., PALLU, S. \& BENHAMOU, C. L. 2011. Low bone accrual is associated with osteocyte apoptosis in alcohol-induced osteopenia. Bone, 49, 543-52.

MAUREL, D. B., PALLU, S., JAFFRE, C., FAZZALARI, N. L., BOISSEAU, N., UZBEKOV, R., BENHAMOU, C. L. \& ROCHEFORT, G. Y. 2012b. Osteocyte apoptosis and lipid infiltration as mechanisms of alcohol-induced bone loss. Alcohol Alcohol, 47, 413-22.

MELLO, N. K. \& MENDELSON, J. H. 1971. A quantitative analysis of drinking patterns in alcoholics. Arch Gen Psychiatry, 25, 527-39.

MENAGH, P. J., TURNER, R. T., JUMP, D. B., WONG, C. P., LOWRY, M. B., YAKAR, S., ROSEN, C. J. \& IWANIEC, U. T. 2010. Growth hormone regulates the balance between bone formation and bone marrow adiposity. J Bone Miner Res, 25, 757-68.

RONIS, M. J., WANDS, J. R., BADGER, T. M., DE LA MONTE, S. M., LANG, C. H. \& CALISSENDORFF, J. 2007. Alcohol-induced disruption of endocrine signaling. Alcohol Clin Exp Res, 31, 1269-85.

SHANKAR, K., LIU, X., SINGHAL, R., CHEN, J. R., NAGARAJAN, S., BADGER, T. M. \& RONIS, M. J. 2008. Chronic ethanol consumption leads to disruption of vitamin D3 homeostasis associated with induction of renal 1,25 dihydroxyvitamin D3-24-hydroxylase (CYP24A1). Endocrinology, 149, 1748-56.

SIBONGA, J. D., IWANIEC, U. T., SHOGREN, K. L., ROSEN, C. J. \& TURNER, R. T. 2007. Effects of parathyroid hormone (1-34) on tibia in an adult rat model for chronic alcohol abuse. Bone, 40, 1013-20.

SIGGINS, R. W., BAGBY, G. J., MOLINA, P., DUFOUR, J., NELSON, S. \& ZHANG, P. 2009. Alcohol exposure impairs myeloid dendritic cell function in rhesus macaques. Alcohol Clin Exp Res, 33, 1524-31.

SPENCER, H., RUBIO, N., RUBIO, E., INDREIKA, M. \& SEITAM, A. 1986. Chronic alcoholism. Frequently overlooked cause of osteoporosis in men. Am J Med, 80, 393-7.

SRIPANYAKORN, S., JUGDAOHSINGH, R., MANDER, A., DAVIDSON, S. L., THOMPSON, R. P. \& POWELL, J. J. 2009. Moderate ingestion of alcohol is associated with acute ethanol-induced suppression of circulating CTX in a PTH-independent fashion. J Bone Miner Res, 24, 1380-8.

This article is protected by copyright. All rights reserved 
TURNER, R. T. 2000. Skeletal response to alcohol. Alcohol Clin Exp Res, 24, 1693-701.

TURNER, R. T., DORAN, E. \& IWANIEC, U. T. 2012. Detrimental effects of alcohol on bone growth. INTECH Open Access Publisher.

TURNER, R. T., KIDDER, L. S., KENNEDY, A., EVANS, G. L. \& SIBONGA, J. D. 2001. Moderate alcohol consumption suppresses bone turnover in adult female rats. J Bone Miner Res, 16, 589-94.

TURNER, R. T., MARTIN, S. A. \& IWANIEC, U. T. 2018. Metabolic coupling between bone marrow adipose tissue and hematopoiesis. Curr Osteoporos Rep, 16, 95-104.

TURNER, R. T., ROSEN, C. J. \& IWANIEC, U. T. 2010. Effects of alcohol on skeletal response to growth hormone in hypophysectomized rats. Bone, 46, 806-12.

VELDHUIS-VLUG, A. G. \& ROSEN, C. J. 2018. Clinical implications of bone marrow adiposity. J Intern Med, 283, 121-139.

VIVIAN, J. A., GREEN, H. L., YOUNG, J. E., MAJERKSY, L. S., THOMAS, B. W., SHIVELY, C. A., TOBIN, J. R., NADER, M. A. \& GRANT, K. A. 2001. Induction and maintenance of ethanol self-administration in cynomolgus monkeys (Macaca fascicularis): long-term characterization of sex and individual differences. Alcohol Clin Exp Res, 25, 1087-97.

WEZEMAN, F. H. \& GONG, Z. 2004. Adipogenic effect of alcohol on human bone marrow-derived mesenchymal stem cells. Alcohol Clin Exp Res, 28, 1091-101.

This article is protected by copyright. All rights reserved 


\section{Figure Legends}

Figure 1. Regions of interest with cancellous bone evaluated in (A) $3^{\text {rd }}$ lumbar vertebral body, (B) core biopsy sampled from the central portion of the $3^{\text {rd }}$ lumbar vertebral body, and $(C)$ histological section.

Figure 2. Effects of 12 months of voluntary ethanol consumption on $(A)$ bone area, $(B)$ bone mineral content, and $(\mathrm{C})$ bone mineral density in lumbar vertebrae 1-4 in male rhesus macaques measured using dual energy $x$-ray absorptiometry. Data are mean \pm SE, $n=9$ for control and 13 for ethanol $(\mathrm{EtOH})$.

Figure 3. Effects of 12 months of voluntary ethanol consumption on ( $A$ and $F$ ) cancellous bone volume fraction, $(B$ and $G$ ) connectivity density, $(C$ and $H)$ trabecular thickness, $(D$ and $I)$ trabecular number, and (E and $\mathrm{J})$ trabecular separation in $3^{\text {rd }}$ lumbar vertebral body and $3^{\text {rd }}$ lumbar vertebral body core biopsy, respectively, in male rhesus macaques measured using microcomputed tomography. Data are mean \pm SE, $n=9$ for control and 13 for ethanol (EtOH).

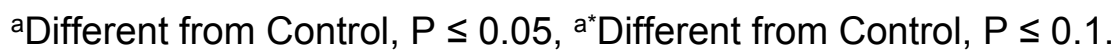

Figure 4. Effects of voluntary ethanol consumption on (A) osteoid area/bone area, $(B)$ osteoid thickness, $(C)$ osteoid perimeter/bone perimeter, (D) osteoblast perimeter/bone perimeter, $(E)$ osteoclast perimeter/bone perimeter, (F) marrow adiposity (marrow adipose tissue area/tissue area), $(\mathrm{G})$ adipocyte density, and $(\mathrm{H})$ adipocyte size in $3^{\text {rd }}$ lumbar vertebra in male rhesus macaques. Data are mean $\pm \mathrm{SE}, \mathrm{n}=9$ for control and 13 for ethanol (EtOH). aDifferent from Control, $\mathrm{P} \leq 0.05, \mathrm{a}^{*}$ Different from Control, $\mathrm{P} \leq 0.1$.

Figure 5. Effects of voluntary ethanol consumption on $(A)$ mineralizing perimeter/bone perimeter, (B) mineral apposition rate, (C) bone formation rate/bone perimeter, (D) bone formation rate/bone area, and $(E)$ bone formation rate/tissue area in $3^{\text {rd }}$ lumbar vertebra in male rhesus macaques. Representative photomicrographs from $(F)$ a control monkey and $(G)$ an ethanol-treated monkey depicting differences in fluorochrome labeling and marrow adiposity. Data are mean $\pm S E, n=9$ for control and 13 for ethanol (EtOH). ${ }^{a}$ Different from Control, $\mathrm{P} \leq 0.05$.

This article is protected by copyright. All rights reserved 
Figure 6. Effects of 12 months of voluntary ethanol consumption on (A) crack density, (B) crack surface density, and $(C)$ crack length in $2^{\text {nd }}$ lumbar vertebra in male rhesus macaques. Data are mean \pm SE, $n=8$ for control and 12 for ethanol $(\mathrm{EtOH})$.

Figure 7. Effects of ethanol consumption on (A) plasma carboxyterminal cross-linking telopeptide of type 1 collagen (CTX), a marker of global bone resorption and (B) plasma osteocalcin, a marker of global bone formation, in male rhesus macaques. Data for individual monkeys are presented at baseline and necropsy in ethanol-treated animals $(n=13)$ and at necropsy in control animals $(n=9)$. Data are also presented as mean $\pm S E$. aDifferent from Baseline, $P \leq 0.05, a^{*} P \leq 0.10$, $\mathrm{b}^{*}$ Different from Control at necropsy, $\mathrm{P} \leq 0.1$.

This article is protected by copyright. All rights reserved 
Table 1. Study population.

Age at study termination (years)

Body weight at study termination $(\mathrm{kg})$

Cumulative ethanol intake $(\mathrm{g} / \mathrm{kg})$

Average ethanol intake $(\mathrm{g} / \mathrm{kg} / \mathrm{d})$

Average daily Calories from ethanol (\%)

Average blood ethanol concentration (mg/dl)

Data are mean \pm SE

\begin{tabular}{ccc} 
Control $(n=9)$ & & Ethanol $(n=13)$ \\
\cline { 1 - 1 } $7.0 \pm 0.3$ & & $7.2 \pm 0.1$ \\
$8.6 \pm 0.7$ & & $9.1 \pm 0.4$ \\
& & $1,077 \pm 79$ \\
& $2.8 \pm 0.2$ \\
& $29.6 \pm 2.4$ \\
& $88.3 \pm 8.8$
\end{tabular}

Control $(n=9)$ 


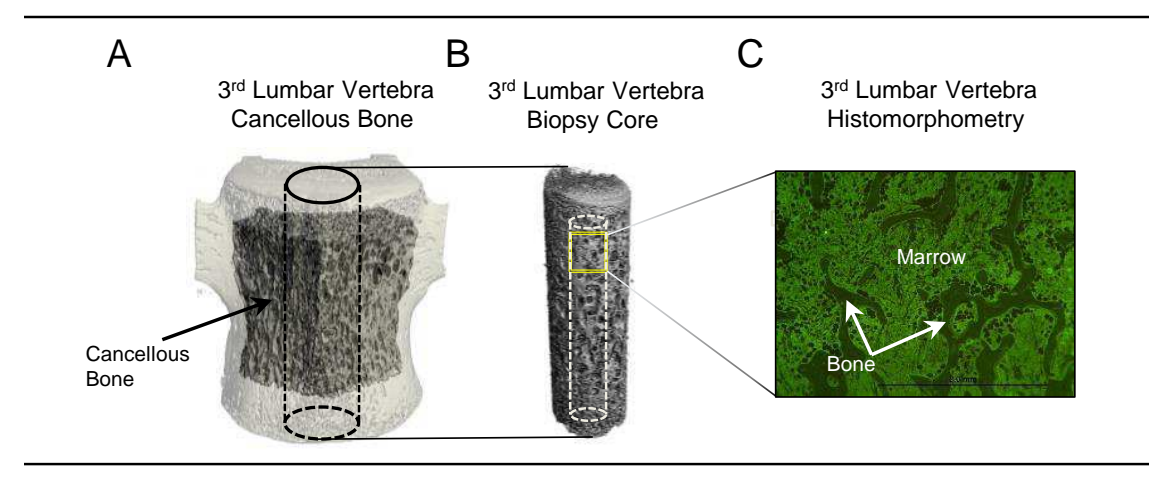

Figure 1 
Lumbar Vertebra 1-4

A

B

Bone Mineral Content

C
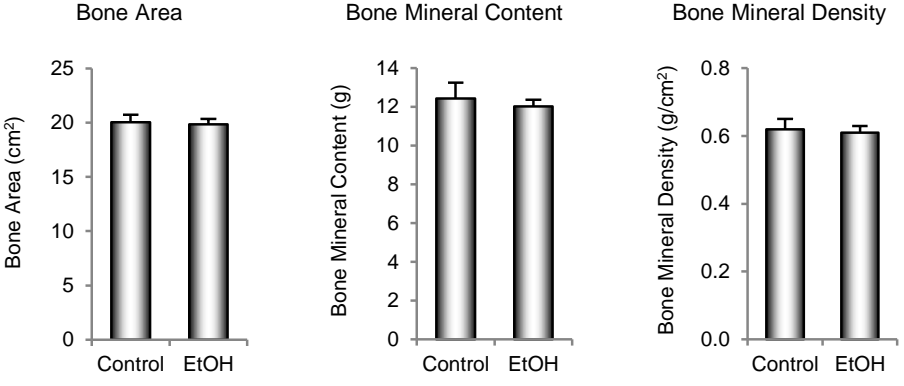

Figure 2 


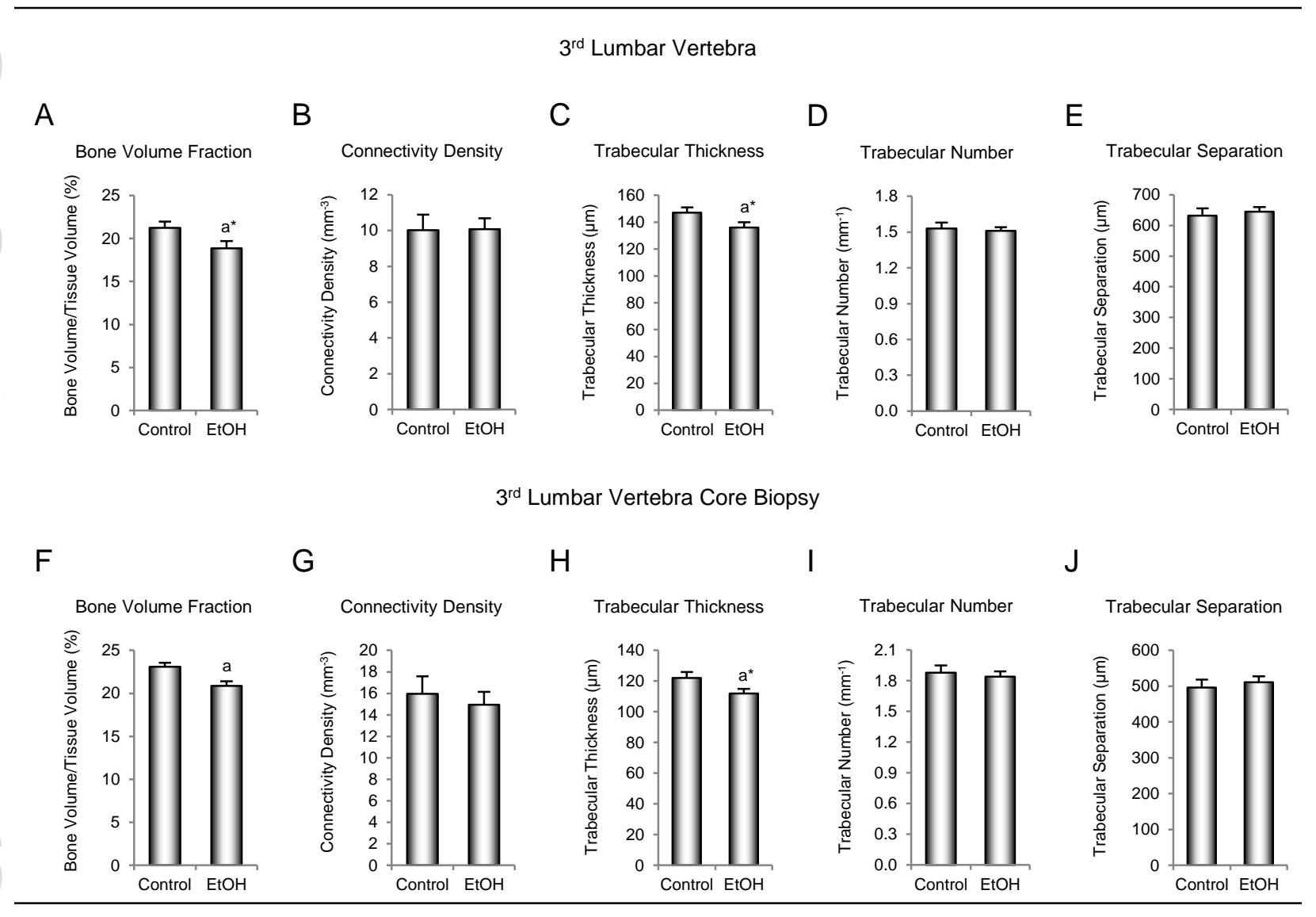

Figure 3 
$3^{\text {rd }}$ Lumbar Vertebra Core Biopsy

A

Osteoid Area

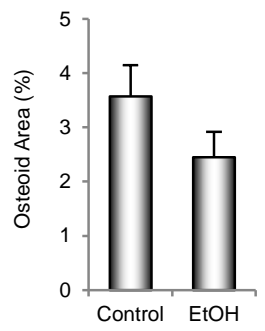

F

Marrow Adiposity

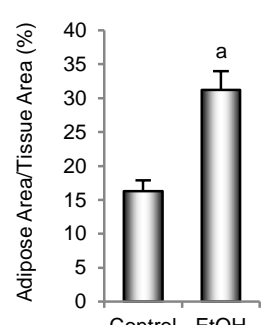

B

Osteoid Thickness

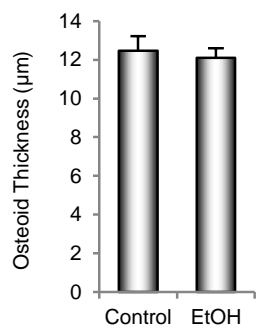

G

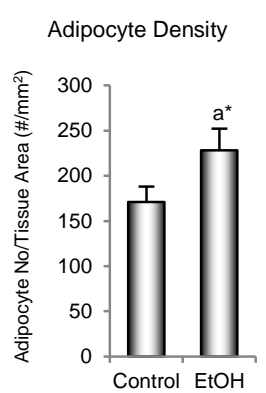

C

Osteoid Perimeter

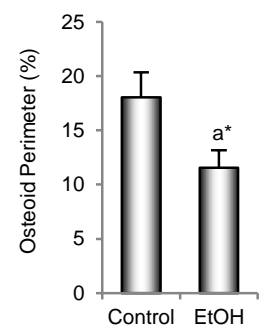

$\mathrm{H}$

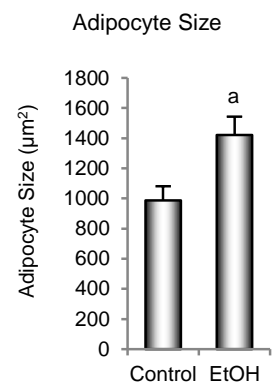

D

Osteoblast Perimeter

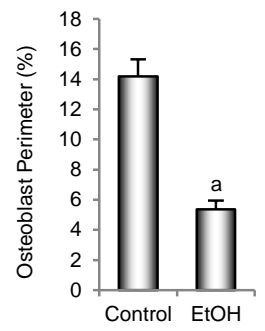

E

Osteoclast Perimeter

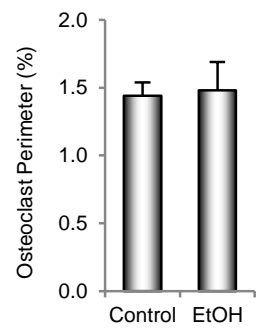

Figure 4 
$3^{\text {rd }}$ Lumbar Vertebra Core Biopsy

A

Mineralizing Perimeter

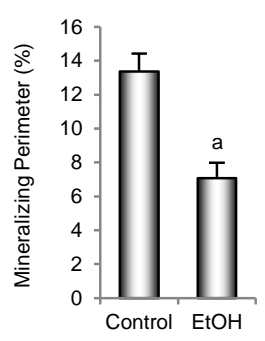

B

Mineral Apposition Rate

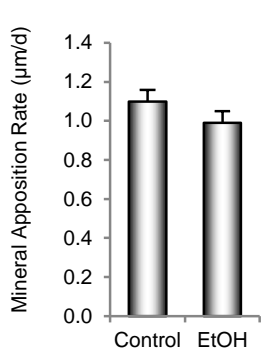

C Bone Formation Rate
(Per Bone Perimeter)

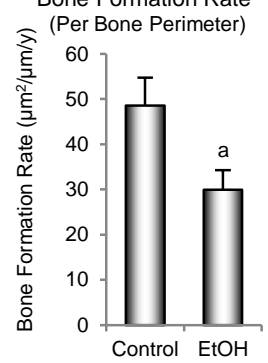

D

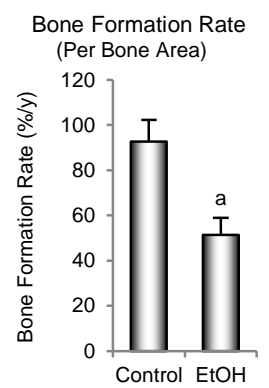

E

Bone Formation Rate (Per Tissue Area)

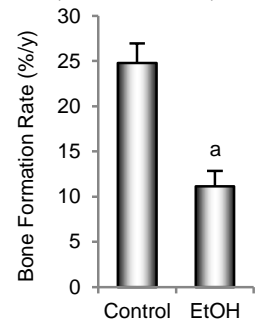

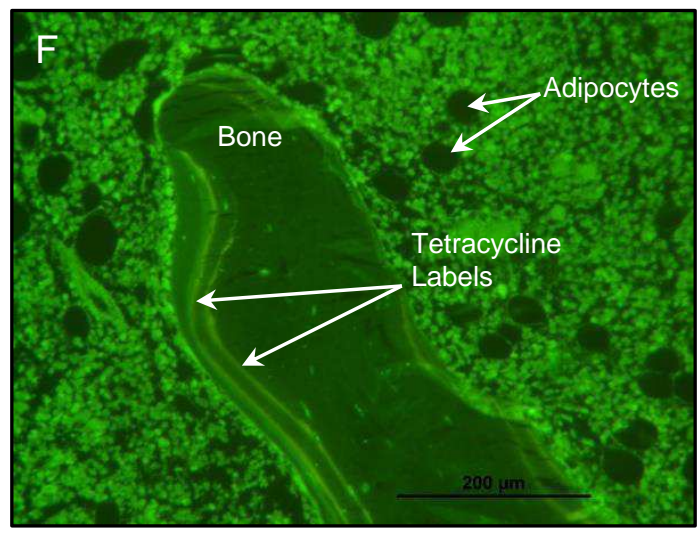

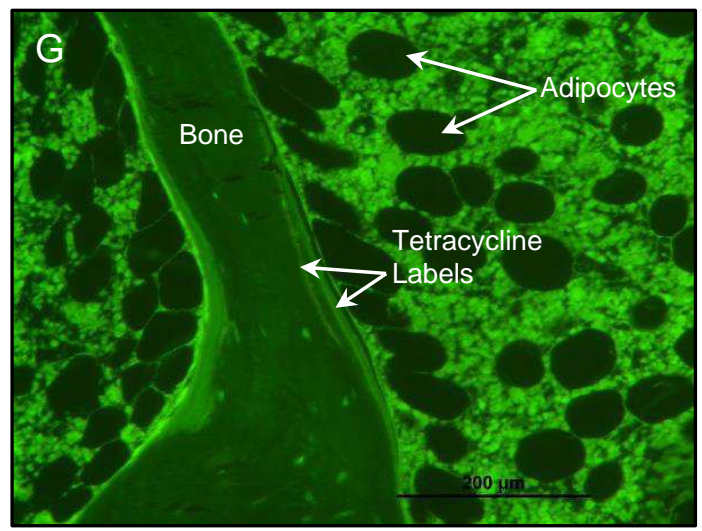

Figure 5 


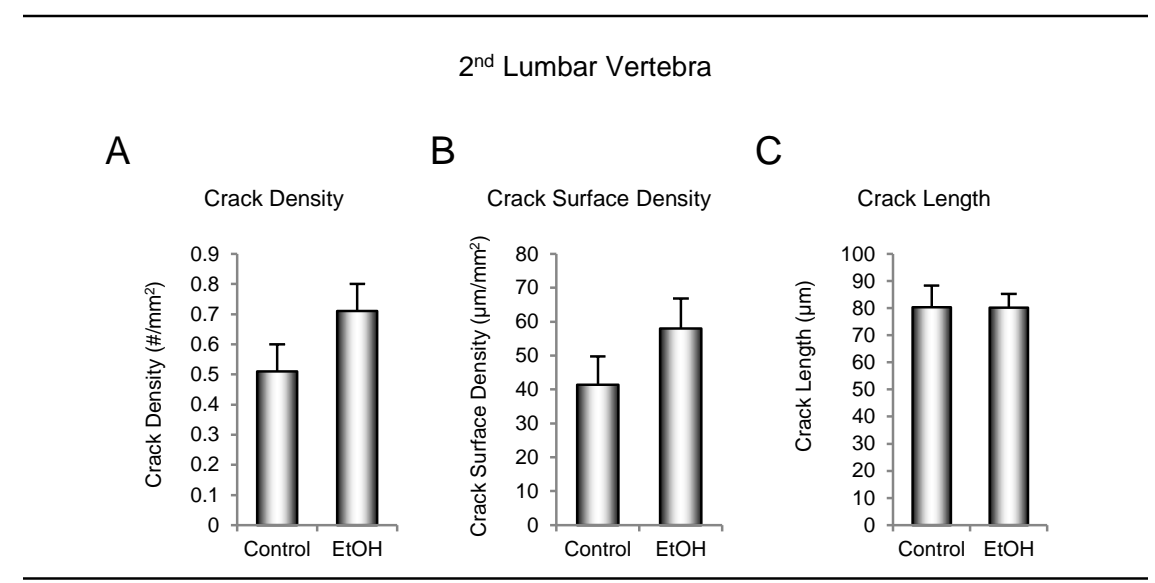

Figure 6 


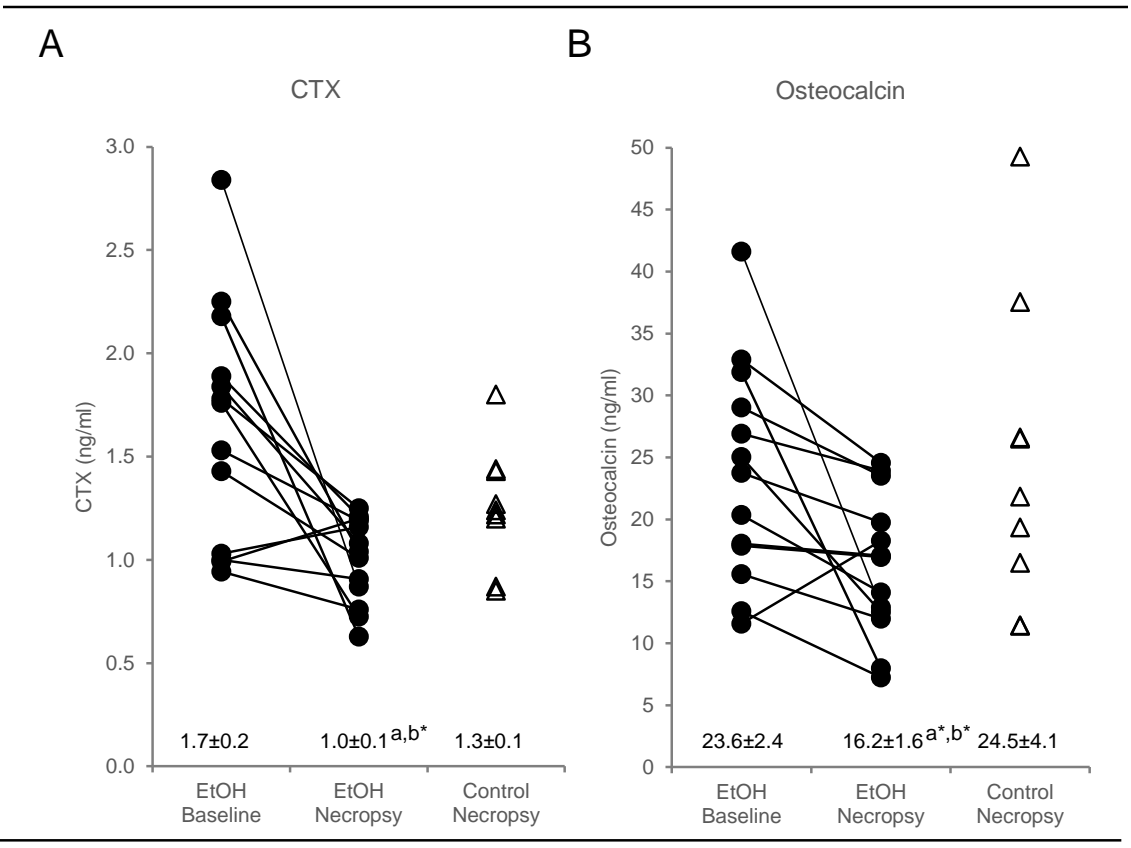

Figure 7

This article is protected by copyright. All rights reserved 